\title{
Differences in Acquisition of Discrete Lever-Press and Shuttle Avoidance Responses in 6 Strains of Mice
}

\author{
Hisashi KURIBARA and Sakutaro TADOKORO \\ Division for Behavior Analysis, Behavior Research Institute, \\ Gunma University School of Medicine, 3-39-22 Showa-machi, \\ Maebashi 371, Japan
}

Accepted October 31, 1985

\begin{abstract}
Characteristics of the acquisition processes of discrete lever-press and shuttle avoidance responses (intertrial interval $=25 \mathrm{sec}$, warning duration $=5 \mathrm{sec}$ with an escape contingency, and 1 session $=1 \mathrm{hr}$ training/day) as well as those of the ambulatory activity were investigated in 6 strains of mice (dd, ICR, BALB/C, $\mathrm{C} 57 \mathrm{BL} / 6, \mathrm{C} 3 \mathrm{H} / \mathrm{He}$ and $\mathrm{DBA} / 2$ ). In the lever-press avoidance situation, the $\mathrm{dd}$, $\mathrm{BALB} / \mathrm{C}$ and $\mathrm{DBA} / 2$ strains demonstrated a good avoidance response, showing average avoidance rates of higher than $80 \%$ within $10-15$ sessions of the training. The $\mathrm{C} 3 \mathrm{H} / \mathrm{He}$ also demonstrated a good avoidance response, though 20 sessions or more of the training were required to attain to the level. The ICR and C57BL/6 strains demonstrated a poorer avoidance response than the other 4 strains, and achieved average avoidance rates of $30-40 \%$. The dd, BALB/c, C3H/He and DBA/ 2 strains also demonstrated a good shuttle avoidance response when they were trained in an experimental box of $50 \mathrm{~cm}$ in width. In contrast, the ICR and C57BL/ 6 strains demonstrated an extremely poor avoidance response in this situation, showing an average avoidance rate of less than 10\%. However, when the dd, ICR and C57BL/6 strains were trained in a shuttle box of $30 \mathrm{~cm}$ in width, they rapidly acquired the avoidance response, and the average avoidance rates finally achieved were much higher than those of the mice trained in the shuttle box of 50 $\mathrm{cm}$ in width. In particular, the $\mathrm{C} 57 \mathrm{BL} / 6$ strain exhibited the best avoidance response among the 3 strains. The ambulatory activity of the C57BL/ 6 strain was less than those of the other 5 strains.
\end{abstract}

Conditioned avoidance response in rodents has been widely applied for preclinical evaluation of psychotropic drugs. Furthermore, the acquisition processes of conditioned avoidance responses have received much attention for evaluation of nootropic and/or antidementia drugs.

In the conditioned avoidance experiments in mice, shuttle-type avoidance has been commonly applied to investigate genetic influence on the acquisition processes and to study the effects of psychotropic drugs (110). We newly assembled an operant chamber for lever-press avoidance response in mice (11) and demonstrated that the dd strain of mice acquired well a discrete lever-press avoidance response (12). We also reported that the changes in the avoidance response induced by several types of psychotropic drugs were qualitatively identical with those in the Wistar strain rats (12-14).

It has been well known that there are marked differences among strains of mice in their behavioral characteristics and in the sensitivity to psychotropic drugs. With respect to the conditioned shuttle avoidance response, many researchers reported strain differences not only in the acquisition processes $(1-7,9,15-17)$, but also in the drug-induced changes in the avoidance response $(1,3,10,15,17)$. However, it should be recognized that the response topographies are different between the shuttle and lever-press avoidance responses. 
In a previous study, we (18) compared the characteristics of the discrete lever-press and shuttle avoidance responses in dd strain mice. It is also necessary to examine strain differences in both types of avoidance responses.

In this study, we investigated the acquisition processes of the discrete lever-press as well as shuttle avoidance responses, having the same temporal parameters, and the ambulatory activities in 6 strains of mice.

\section{Materials and Methods}

\section{Animals}

The experimental animals were male mice of dd, ICR, BALB/c, C57BL/6, C3H/He and $D B A / 2$ strains. The color of body hair of the dd, ICR and BALB/C strains was white, and those of the $\mathrm{C} 57 \mathrm{BL} / 6, \mathrm{C} 3 \mathrm{H} / \mathrm{He}$ and $\mathrm{DBA} / 2$ strains were black, gray and brown, respectively. The dd strain mice were provided by the Institute of Experimental Animal Research, Gunma University School of Medicine, and the other 5 strains of mice were purchased from Charles River Japan, Inc. (Atsugi). These mice were housed in groups of $8-10$ in aluminum or acrylfiber cages of $30(W) \times 20$ (D) $\times 10(\mathrm{H}) \mathrm{cm}$ with a wooden-flake floor mat (White-Flake: Charles River Japan, Inc.), and the animals were freely given solid diet (MF: Oriental Yeast Co., Tokyo) and tap water except during times of the experiment. The breeding room was controlled so that the light-dark schedule (light period: 6:00$18: 00)$ and room temperature $\left(23 \pm 2^{\circ} \mathrm{C}\right)$ were relatively constant. When the mice were 10 weeks of the age and weighed 28-32 $\mathrm{g}$ in the dd and ICR strains, and 23-28 $\mathrm{g}$ in the $\mathrm{BALB} / \mathrm{C}, \mathrm{C} 57 \mathrm{BL} / 6, \mathrm{C} 3 \mathrm{H} / \mathrm{He}$ and $\mathrm{DBA} / 2$ strains, the training in the discrete leverpress or shuttle avoidance situation was started. Numbers of the mice trained in the avoidance situations are presented in Figs. $1-3$. In addition, the other 20 mice of each strain were used in the experiment to study ambulatory activity. The experiment was carried out at the age of 12 weeks.

\section{Apparatus and procedure}

1) Avoidance: Three equivalent sets of the behavior-controlling and data-recording apparatus (GT-7705 and GT-7715, respectively: O'Hara \& Co., Ltd., Tokyo), which were the same as those used in our previous experiment (11-14), were used in the present experiment.

The experimental box for the lever-press avoidance (GT-8310; O'Hara \& Co., Ltd.) was made of acrylfiber and aluminum boards with dimensions of $18(\mathrm{~W}) \times 9(\mathrm{D}) \times 10(\mathrm{H})$ $\mathrm{cm}$. A stainless steel lever of $2 \mathrm{~cm}$ in width and $5 \mathrm{~cm}$ in length, which could be activated with a force of more than $1.5 \mathrm{~g}$, was vertically set in the side wall $1 \mathrm{~cm}$ over the floor grid at the bottom. A speaker for presenting a warning stimulus was set in the ceiling. The box was used only for the experiment in mice.

Two different sizes of the experimental boxes for the shuttle avoidance were used in the present experiment. They were made of acrylfiber and aluminum boards. The dimensions of the larger box (GT-7750; O'Hara \& Co., Ltd.) were 50 (W) $\times 15$ (D) $\times 20(\mathrm{H}) \mathrm{cm}$ with 2 photo-beams arranged $36 \mathrm{~cm}$ apart, and the dimensions of the smaller box (GT-8450; O'Hara \& Co., Ltd.) were $30 \quad(W) \times 9 \quad(D) \times 15 \quad(H) \quad c m$ with 2 photo-beams arranged $18 \mathrm{~cm}$ apart. A speaker for presenting a warning stimulus was set in the ceiling of each box. These boxes were used only for the experiment in mice.

The temporal parameters of the discrete avoidance schedule (19) were as follows: an intertrial interval of $25 \mathrm{sec}$ and a warning duration of $5 \mathrm{sec}$. The warning stimulus was an $800 \mathrm{~Hz}$ pure tone from the speaker. The shock was an electric current of 100-150 V. $0.3-0.5 \mathrm{~mA}, 50 \mathrm{~Hz} \mathrm{AC}$, and was given to the mouse through the stainless steel floor grid of the experimental box. The shock intensity was individually controlled according to the sensitivity of the mouse to the shock. The maximum duration of the shock presentation was $3 \mathrm{sec}$, and an escape contingency was inserted in the schedule. Each session consisted of $1 \mathrm{hr}$ training per day (120 avoidance trials/session) and was held every other day for a total of 12-15 sessions or more. The indices of the avoidance response were response rate (lever-pressings or shuttlings/ $\mathrm{min}$ ) and avoidance rate (number of avoidance responses/number of avoidance trials). The avoidance experiment was carried out between 9:00-18:00. 
2) Ambulatory activity: For measurement of the ambulatory activity of the mouse, a tilting-type ambulometer of $20 \mathrm{~cm}$ in diameter (AM-10; O'Hara \& Co., Ltd.) (20) was used. A mouse was put into the plexiglas activity cage, and the ambulatory activity counts were recorded for $60 \mathrm{~min}$. The experiment was carried out between 13:00-15:00.

\section{Results}

\section{Acquisition of the avoidance responses}

1) Lever-press avoidance: Figure 1 shows acquisition processes of the discrete leverpress avoidance response in the 6 strains of mice in terms of the average response rate (upper panel), the average avoidance rate (middle panel) and the percentages of the mice showing an avoidance rate of higher than $75 \%$ (lower panel), which were considered to be good performers. There was a marked difference in the acquisition processes among the strains of mice. The $d d, B A L B / c$ and $\mathrm{DBA} / 2$ strains acquired well the avoidance response, and they showed average avoidance rates of about $80 \%$ within 15 sessions of the training. The ICR, C $57 \mathrm{BL} / 6$ and $\mathrm{C} 3 \mathrm{H} / \mathrm{He}$ strains failed to achieve such a high level of the average avoidance rate until the 15th session, showing average avoidance rates of $50-60 \%$ in the 15 th session. When the training was continued, however, the $\mathrm{C} 3 \mathrm{H} / \mathrm{He}$ strain finally showed an average avoidance rate as high as those of the dd, $B A L B / C$ and $D B A / 2$ strains, although the ICR and $\mathrm{C} 57 \mathrm{BL} / 6$ strains exhibited no marked improvement of the avoidance rate (not shown in the figure). Finally, nearly $80 \%$ of the mice in the $d d, B A L B / c, C 3 H / H e$ and DBA/2 strains achieved a critical level of the avoidance rate (75\%), while only $30-40 \%$ of the mice in the ICR and C57BL/6 strains achieved the critical level. The average response rates were relatively higher in the $\mathrm{dd}$ and ICR strains, and they were lower in the $B A L B / C$ and $D B A / 2$ strains than the other strains.

2) Shuttle avoidance response in the larger box: Figure 2 shows acquisition processes of the discrete shuttle avoidance response in the 6 strains of mice, which were trained in the larger box of $50 \mathrm{~cm}$ in width, in the same way as in Fig. 1. The rank order of the average avoidance rates was almost the same as that observed in the lever-press avoidance situation. Thus, the dd, BALB/C, $\mathrm{C} 3 \mathrm{H} / \mathrm{He}$ and
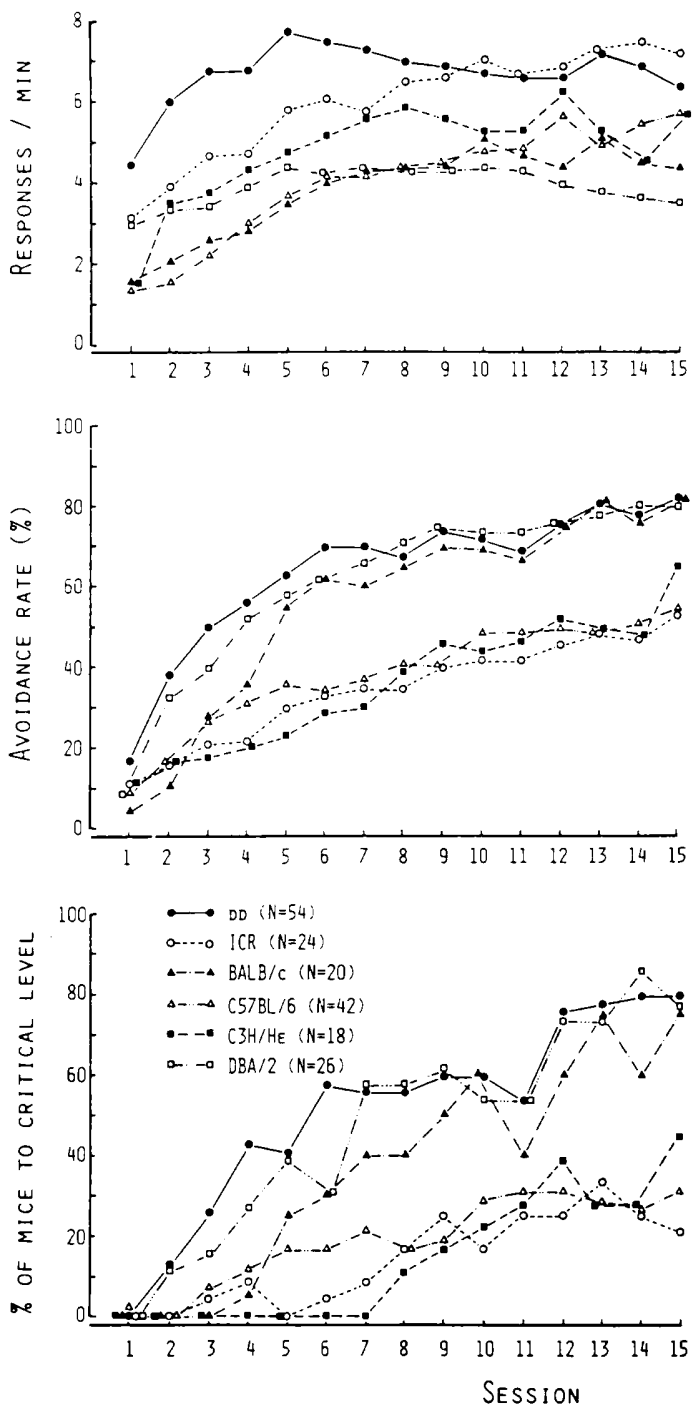

Fig. 1. Acquisition processes of the discrete leverpress avoidance response (intertrial interval $=25 \mathrm{sec}$. warning duration $=5 \mathrm{sec}$ with an escape contingency, and 1 session=1 $\mathrm{hr}$ performance/day) in the $\mathrm{dd}$. ICR, BALB/C, $\mathrm{C} 57 \mathrm{BL} / 6, \mathrm{C} 3 \mathrm{H} / \mathrm{He}$ and $\mathrm{DBA} / 2$ strains of mice. The training was carried out every other day. Upper panel: The average response rate (number of lever-pressings/min). Middle panel: The average avoidance rate (number of avoidance responses/number of avoidance trials). Lower panel: The percentages of occurrence of mice achieving the critical level of avoidance rate of $75 \%$. 
DBA/2 strains acquired well the shuttle avoidance response within 10 sessions of the training, and they exhibited average avoidance rates of higher than $80 \%$. As demonstrated in the lever-press avoidance situation, the acquisition of the shuttle avoidance response in the $\mathrm{C} 3 \mathrm{H} / \mathrm{He}$ strain was
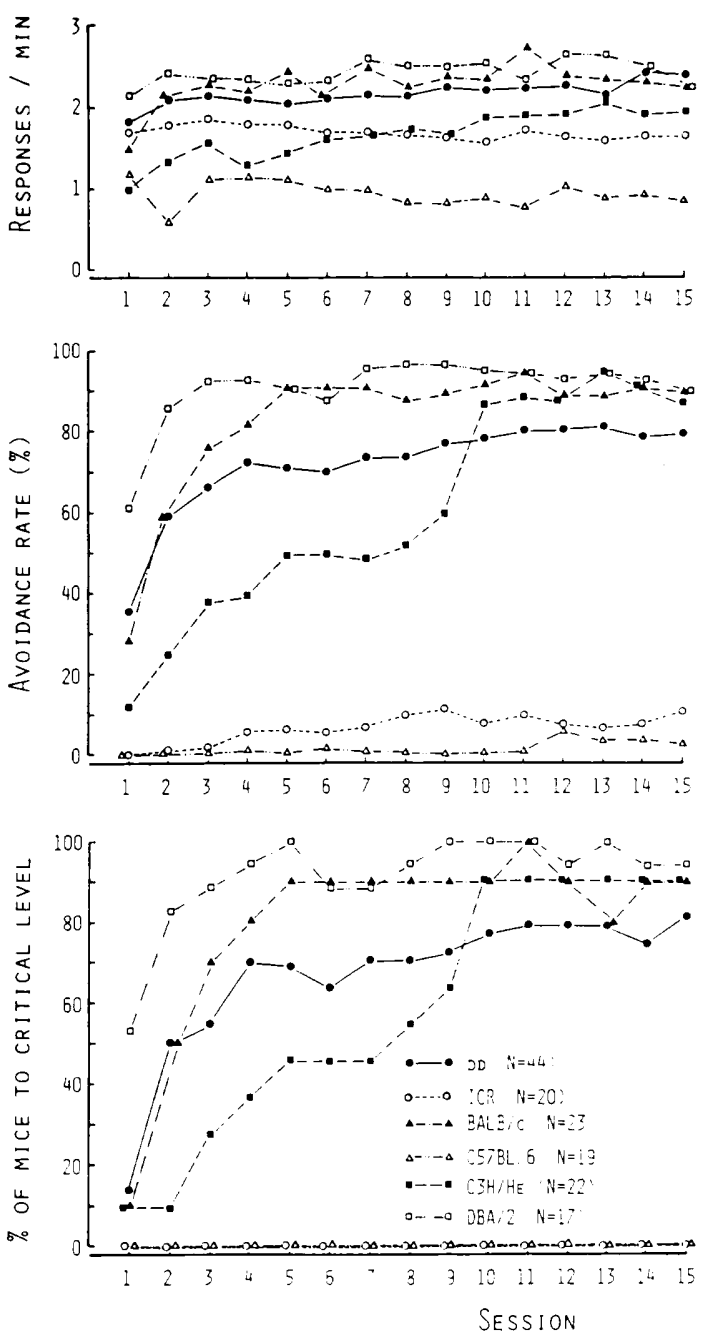

Fig. 2. Acquisition processes of the discrete shuttle avoidance response in the $d d, I C R, B A L B / C$, $\mathrm{C} 57 \mathrm{BL} / 6, \mathrm{C} 3 \mathrm{H} / \mathrm{He}$ and $\mathrm{DBA} / 2$ strains of mice. In this experiment, a shuttle box of $50 \mathrm{~cm}$ in width was used. The temporal parameters of the avoidance schedule were the same as those in the lever-press avoidance situation as described in Fig. 1. The data are shown in the same way as in Fig. 1. However, the response was a shuttling. more delayed than those in the dd, BALB/C and $\mathrm{DBA} / 2$ strains. In the 10th session and later, $80 \%$ or more of the mice in the $\mathrm{dd}$, $\mathrm{BALB} / \mathrm{C}, \mathrm{C} 3 \mathrm{H} / \mathrm{He}$ and $\mathrm{DBA} / 2$ strains achieved a critical level of the avoidance rate. There was no marked difference in the average avoidance rates as well as the percentages of the mice showing the critical level of the avoidance rate between the lever-press and shuttle avoidance situations in these 4 strains. However, the acquisition speed was faster in the shuttle avoidance situation than in the lever-press avoidance situation. In contrast, the acquisition of the shuttle avoidance response in the ICR and C57BL/6 strains was extremely inferior to the other 4 strains. The average avoidance rates of the $\mathrm{ICR}$ and $\mathrm{C} 57 \mathrm{BL} / 6$ strains were always less than $10 \%$ throughout 15 sessions of the training, and there was no case which exhibited an avoidance rate of higher than $75 \%$. Although the training was continued. these 2 strains did not show an improvement of the avoidance response. The average response rate of the $\mathrm{C} 57 \mathrm{BL} / 6$ strain was comparatively lower than those of the other 5 strains.

3) Shuttle avoidance response in the smaller box: Figure 3 shows acquisition processes of the discrete shuttle avoidance response in the dd, ICR and C57BL/6 strains, which were trained in the smaller box of $30 \mathrm{~cm}$ in width, in the same way as in Figs. 1 and 2. The acquisition speeds were faster in the smaller box than in the larger box. Furthermore, the average response and avoidance rates finally established as well as the percentages of mice achieving the critical level were higher in the smaller box than in the larger box. The most interesting result was observed in the C57BL/ 6 strain. Although the C57BL/6 strain exhibited the lowest avoidance rate in the lever-press situation and in the shuttle situation using the larger box, this strain excellently acquired the shuttle avoidance response in the smaller box within the 2nd session of the training, showing the best acquisition among the 3 strains. In contrast, the ICR strain demonstrated the poorest result in this situation as well as in the lever-press situation and shuttle situation using the larger box. However, there was no 

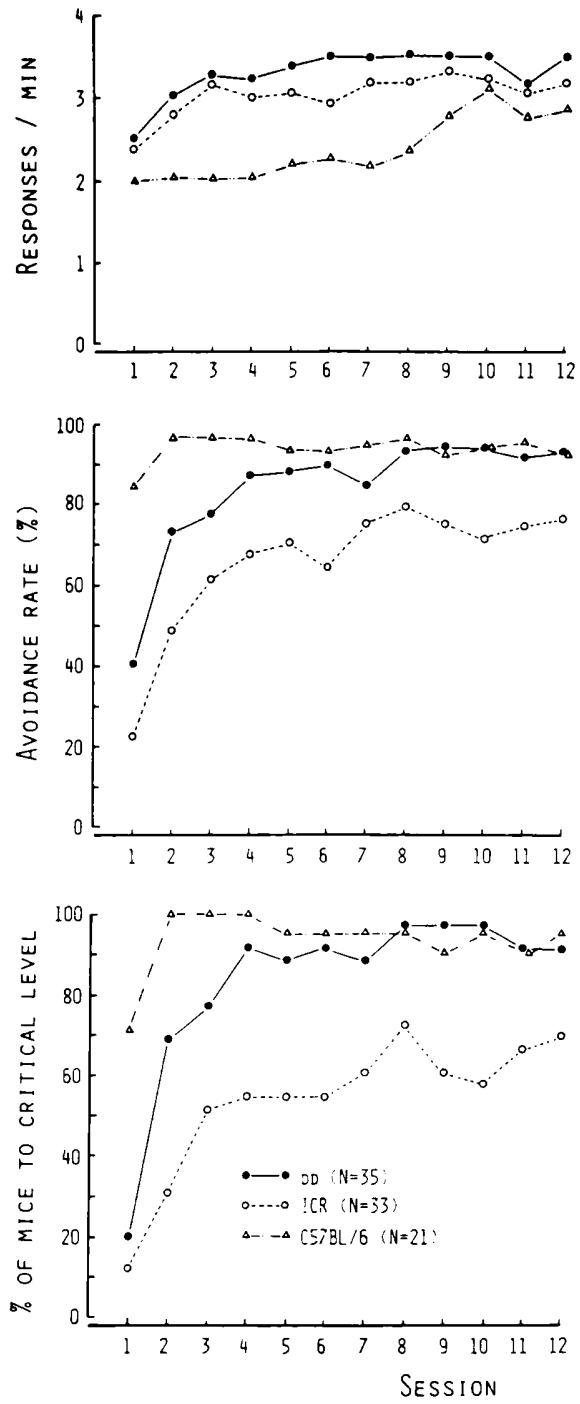

Fig. 3. Acquisition processes of the discrete shuttle avoidance response in the $\mathrm{dd}, \mathrm{ICR}$ and C57BL/ 6 strains of mice. In this experiment, a shuttle box of $30 \mathrm{~cm}$ in width was used. The temporal parameters of the avoidance schedule were the same as those in the lever-press avoidance situation as described in Fig. 1. The data are shown in the same way as in Figs. 1 and 2.

marked difference in the response rates among the 3 strains.

Ambulatory activity: Figure 4 shows the ambulatory activity counts during $1 \mathrm{hr}$ observation period in the 6 strains of mice. The average activity count of the $\mathrm{C} 57 \mathrm{BL} / 6$

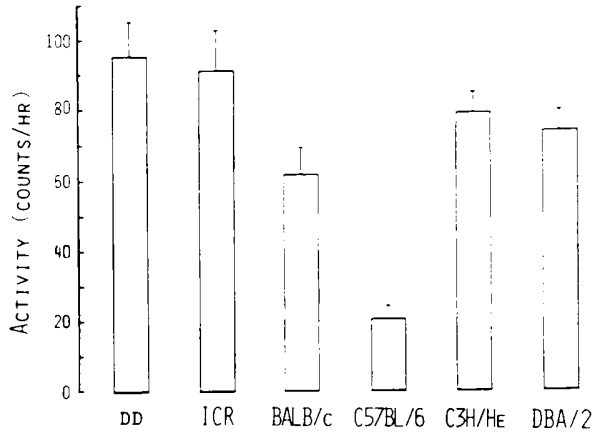

Fig. 4. Ambulatory activity counts in the dd, ICR. $\mathrm{BALB} / \mathrm{C}, \mathrm{C} 57 \mathrm{BL} / 6, \mathrm{C} 3 \mathrm{H} / \mathrm{He}$ and $\mathrm{DBA} / 2$ strains of mice. The ambulatory activity of each mouse was measured for $1 \mathrm{hr}$ with a tilting-type ambulometer. Twenty mice of each strain were used in this experiment. The $\mathrm{C} 57 \mathrm{BL} / 6$ strain showed a significantly lower activity count than those of the other 5 strains ( $P<0.01$, Student's $t$-test). The BALB/C strain showed a significantly lower activity count than the dd and ICR strains $(P<0.01$ and 0.05 , respectively).

strain was significantly less than those of the other 5 strains $(P<0.01$. Student's $t$-test $)$. The average activity count of the BA.LB/C strain was significantly less than those of the dd and ICR strains $(P<0.01$ and 0.05 , respectively).

\section{Discussion}

The present experiment demonstrated that there were marked differences in the acquisition of the discrete lever-press and shuttle avoidance responses among 6 strains of mice. In the lever-press avoidance situation, the dd, BALB/C, $\mathrm{C} 3 \mathrm{H} / \mathrm{He}$ and $\mathrm{DBA} / 2$ strains acquired well the avoidance response, while the $\mathrm{ICR}$ and $\mathrm{C} 57 \mathrm{BL} / 6$ strains showed comparatively poorer avoidance response than the other 4 strains. A similar result was also demonstrated in the shuttle avoidance situation using the larger box. These results are almost identical with those reported by Bovet et al. (1) and Oliverio (15) except for the result in the $\mathrm{C} 3 \mathrm{H} / \mathrm{He}$ strain. They reported that the $\mathrm{C} 57 \mathrm{BL} / 6$ and $\mathrm{C} 3 \mathrm{H} / \mathrm{He}$ strains were much inferior to the $\mathrm{DBA} / 2$ strain in the acquisition of the discrete shuttle avoidance response in which a light was presented as the conditioned stimulus. However, it has been well-known that the 
$\mathrm{C} 3 \mathrm{H} / \mathrm{He}$ strain has rodless retinas and that this strain acquired fairly well the avoidance response in a discrete shuttle avoidance situation in which buzzer tone was used as the conditioned stimulus $(2,21,22)$ or in a continuous shuttle avoidance situation in which no conditioned stimulus was presented (17). It is therefore important to select the conditioned stimulus to study acquisition of the discrete avoidance response in mice. However, the retardation of the acquisition observed in the $\mathrm{C} 3 \mathrm{H} / \mathrm{He}$ strain may reflect the visual dysfunction.

On the other hand, when the dd, ICR and C57BL/6 strains were trained in the shuttle avoidance situation using the smaller box, the acquisition in these mice progressed more rapidly than in mice trained in the larger box. In particular, the acquisition of the $\mathrm{C} 57 \mathrm{BL} / 6$ strain was superior to that of the dd strain, and the former strain demonstrated an establishment of a high level of the avoidance rate within the 2 nd session. The average response rate of the $\mathrm{C} 57 \mathrm{BL} / 6$ strain was lower than the other 5 strains in the shuttle avoidance situation using the larger box. However, there was no marked difference in the response rate among the $d d, I C R$ and C57BL/6 strains in the shuttle avoidance situation using the smaller box. In the shuttle avoidance situation, the mouse has to move in the excerimental box. Thereby, the general activity level of the mouse may strongly affect the acquisition of the shuttle avoidance response. In fact, Messeri et al. (4) and Oliverio et al. (5) reported that the acquisition of the shuttle avoidance response was closely correlated, showing a correlation coefficient of higher than 0.7, with the general activity level. The $\mathrm{C} 57 \mathrm{BL} / 6$ strain exhibited a much lower ambulatory activity as well as a lower response rate in the shuttle avoidance situation using the larger box. It is therefore considered that the inferior avoidance response in the C57BL/6 strain, which was demonstrated in the lever-press situation and in the shuttle situation of the larger box, is not simply due to a lower learning ability, but rather partially reflects a lower level of general activity. In contrast, the ICR strain exhibited an inferior avoidance response to the other strains in the lever- press avoidance situation as well as in the shuttle avoidance situation using both the larger and smaller boxes. This result suggests that the learning ability of the ICR strain is lower than those of the other 5 strains in the avoidance situation of both lever-press and shuttle types.

In addition to the general activity level, there may be many other factors which are involved in the mouse strain difference in the acquisition of conditioned avoidance response.

It has been well-known that the shock intensity affects the acquistion of the avoidance response. However, in the present experiment, we individually controlled the shock intensity according to the sensitivity of the mice. Furthermore, Oliverio and Castellano (23) reported that there was no remarkable difference in the shock sensitivity between $\mathrm{C} 57 \mathrm{BL} / 6$ and DBA/2 strains. Presumably, the shock sensitivity may not be a main factor for the strain difference.

It has been reported that there are marked differences in the neural activities in the brain, including acetylcholine (24-32), catecholamines $(24,26,33-43)$, serotonin $(24,44)$, GABA (24) systems, etc. among strains of mice. However, it is difficult to obtain a definite correlation betwen the acquisition of the avoidance response and the neurochemical data by the present experiment. In this respect, a further study is required.

However, it can be concluded from the present results that there are marked differences in the acquisition of the discrete avoidance response among strains of mice and that the acquisition varies depending on many factors. When we study the acquisition process of the avoidance response in mice, such factors should be considered in the data analysis.

\section{References}

1 Bovet, D., Bovet-Nitti, F. and Oliverio, A.: Genetic aspects of learning and memory in mice. Science 163, 139-149 (1969)

2 Collins, R.L.: Inheritance of avoidance conditioning in mice: A diallel study. Science 143, 1188-1190 (1964)

3 Fuller, J.L.: Strain differences in the effects of chlorpromazine and chlordiazepoxide upon 
active and passive avoidance in mice. Psychopharmacologia (Berlin) 16, 261-271 (1970)

4 Messeri, P., Oliverio, A. and Bovet, D.: Relation between avoidance and activity: A diallel study in mice. Behav. Biol. 7, 733-742 (1972)

5 Oliverio, A., Castellano, C. and Messeri. P.: A genetic analysis of avoidance, maze and wheel running behaviors in the mouse. J. Comp. Physiol. Psychol. 79, 459-473 (1972)

6 Oliverio, A., Eleftheriou, B.E. and Bailey, D.W.: A gene influencing active avoidance performance in mice. Physiol. Behav. 11, 497-502 (1973)

7 Royce, J.R. and Covington, M.: Genetic differences in the avoidance conditioning of mice. J. Comp. Physiol. Psychol. 53, 197-200 (1960)

8 Schlesinger, K. and Wimer, R.E.: Genotype and conditioned avoidance learning in the mouse. J. Comp. Physiol. Psychol. 63, 139-141 (1967)

9 Wahlsten, D.: Genetic experiments with animal learning: A critical review. Behav. Biol. 7, 143182 (1972)

10 Wahlsten, D.: Phenotype and genotype relations between initial response to electric shock and rate of avoidance learning in mice. Behav. Genet. 2, 211-240 (1972)

11 Kuribara, H., Hirabayashi, M. and Tadokoro, S.: Conditioned lever-press avoidance response in mice and effects of psychotropic drugs thereon. Japan. J. Pharmacol. 33, Supp., 215P (1983)

12 Kuribara, H. and Tadokoro, S.: Conditioned lever-press avoidance in mice: Acquisition processes and effects of diazepam. Psychopharmacology (Berlin) 82, 36-40 (1984)

13 Kuribara, H. and Tadokoro, S.: Comparison of susceptibilities to the effects of antipsychotic drugs on lever-press avoidance responses between mice and rats. Japan. J. Pharmacol. 33, 1127-1133 (1983)

14 Kuribara, $H$. and Tadokoro, S.: Differences in cholinergic agonist- and cholinergic antagonistinduced changes in avoidance responses between dd mice and Wistar rats. Japan. J. Psychopharmacol. 3, 159-166 (1983)

15 Oliverio, A.: Genetic factors in the control of drug effects on the behaviour of mice. In The Genetics of Behaviour. Edited by Van Abeelen. J.H.F., p. 375-395, North-Holland Pub. Co., Amsterdam (1974)

16 Oliverio, A.: Genetic and environmental factors in relation to behavioral regidity and plasticity. In Neurobiological Basis of Learning and Memory, Edited by Tsukada $Y$. and Agranoff, B.W., p. 193-212, John Wiley \& Sons Inc., New York (1980)

17 Sekiguchi, S.: Strain differences of mice for open field behaviour, circadian rhythms, and morphine reactivity. Med. Fac. Educ. Shiga Univ. Hum. Soc. Ped. No. 32, p. 93-107 (1982)

18 Kuribara, H., Haraguchi, $H$. and Tadokoro, S.: Comparisons between discrete lever-press and shuttle avoidance responses in mice: Acquisition processes and effects of psychoactive drugs. Japan. J. Pharmacol. 38, 141-151 (1985)

19 Hoffman, H.S., Fleshler, M. and Chorney, H.: Discriminated bar press avoidance. J. Exp. Anal. Behav. 4, 309-316 (1961)

20 Hirabayashi, M.. lizuka, M. and Tadokoro, S.: Simple and easy method for measurement of ambulatory activity in mice. Folia Pharmacol. Japon. 74, 629-639 (1978) (Abs. in English)

21 Duncan, N.C., Grossen, N.E. and Hunt, E.B.: Apparent memory differences in inbred mice produced by different reaction to stress. J. Comp. Physiol. Psychol. 74, 383-389 (1971)

22 Stasik, J.H.: Inheritance of T-maze learning in mice. J. Comp. Physiol. Psychol. 71, 251-257 (1970)

23 Oliverio, A. and Castellano, C.: Genotypedependent sensitivity and tolerance to morphine and heroin: Dissociation between opiate-induced running and analgesia in the mouse. Psychopharmacologia (Berlin) 39, 13-22 (1974)

24 Al-Ani, A.T., Tunnicliff, G., Rick, G.T. and Kerkut, G.A.: GABA production, acetylcholinesterase activity and biogenic amire levels in brain for mouse strains differing in apontaneous activity and reactivity. Life Sci. 9, 21-27 (1970)

25 Durkin, T., Ayad, G., Ebel, A. and Mandel, P.: Regional acetylcholine turnover rates in the brains of three inbred strains of mice: Correlation with some interstrain behavioural differences. Brain Res. 136, 475-486 (1977)

26 Durkin, T.P., Hashem-Zadeh, H., Mandel, P., Kempf, J. and Ebel, A.: Genotypic variation in the dopaminergic inhibitory control of striatal and hippocampal cholinergic activity in mice. Pharmacol. Biochem. Behav. 19, 63-70 (1983)

27 Ebel, A., Hermetet, J.C. and Mandel, P.: Comparative study of acetylcholinesterase and choline acetyltransferase activity in the brain of DBA and C57 mice. Nature New Biol. 242, 5657 (1973)

28 Jaffard, R., Ebe!, A., Destrade, C., Durkin, T., Mandel, P. and Cardo, B.: Effects of hippocampal electric stimulation on long-term memory and cholinergic mechanisms in three inbred strains of mice. Brain Res. 133, 277-289 (1977)

29 Jaffard, R., Destrade, C., Durkin, T. and Ebel, A.: Memory formation as related to genotypic or experimental variations of hippocampal 
cholinergic activity in mice. Physiol. Behav. 22, 1093-1096 (1979)

30 Marks, M.J., Patinkin, D.M., Artman, L.D., Burch, J.B. and Collins, A.C.: Genetic influences on cholinergic drug response. Pharmacol. Biochem. Behav. 15, 271-279 (1981)

31 Marks, M.J., Burch, J.B. and Collins, A.C.: Genetics of nicotine response in four inbred strains of mice. J. Pharmacol. Exp. Ther. 226, 291-302 (1983)

32 Smolen, A., Smolen, T.N., Wehner, J.M. and Collins, A.: Genetically determined differences in acute responses to diisopropylfluorophosphate. Pharmacol. Biochem. Behav. 22, 623-630 (1985)

33 Baker, H., Joh, T.H. and Reis, D.J.: Genetic control of number of midbrain dopaminergic neurons in inbred strains of mice: Relationship to size and neuronal density of the striatum. Proc. Natl. Acad. Sci. U.S.A. 77, 4369-4373 (1980)

34 Baker, H., Joh, T.H. and Reis, D.J.: Time of appearance during development of differences in nigro-striatal tyrosine hydroxylase activity in two inbred mouse strains. Dev. Brain Res. 4, 157-165 (1982)

35 Boehme, R.E. and Ciaranello, R.D.: Dopamine receptor binding in inbred mice: Strain differences in mesolimbic and nigrostriatal dopamine binding sites. Proc. Natl. Acad. Sci. U.S.A. 78, 3255-3259 (1981)

36 Ciaranello, R.D., Barchas, R., Kessler, S. and Barchas, J.D.: Catecholamines: Strain differences and biosynthetic enzyme activity in mice. Life Sci. 11, 665-672 (1972)

37 Eleftheriou, B.E.: Regional brain norepinephrine turnover rates in four strains of mice. Neuro- endocrinology 7, 329-336 (1971)

38 Fink, J.S. and Reis, D.J.: Genetic variations in midbrain dopamine cell number: Parallel with differences in response to dopaminergic agonists and in naturalistic behaviors mediated by central dopaminergic systems. Brain Res. 222, 335-349 (1981)

39 Fink, J.S., Swerdloff, A. and Reis, D.J.: Genetic control of dopamine receptors in mouse caudate nucleus: Relationship of cataleptic response to neuroleptic drugs. Neurosci. Lett. 32, 301-306 (1982)

40 Kassler, S., Ciaronello, R.D., Shirp, J.G.M. and Barcha, S.J.D.: Genetic variation in activity of enzymes involved in synthesis of catecholamines. Proc. Natl. Acad. Sci. U.S.A. 69, 2448-2450 (1972)

41 Lucyna, J.M., Antkiewics-Michaluk, L., RokoszPelc, A., Sansone, M., Oliverio, A. and Vetulani, J.: Dopamine receptors in the striatum and limbic system of various strains of mice: Relation to differences in response to apomorphine. Pharmacol. Biochem. Behav. 17, 11151118 (1982)

42 Severson, J.A., Randall, P.K. and Finch, C.E.; Genotypic influences on striatal dopaminergic regulation in mice. Brain Res. 210, 207-215 (1981)

43 Wolf, M.D., Wilcox, R.E., Riffee, W.H. and Abraham, L.D.: Strain differences in dopamine receptor function and the initiation of movement. Pharmacol. Biochem. Behav. 13, 5-7 (1980)

44 Maruyama, Y., Hayashi, G., Smits, S.E. and Takemori, A.E.: Studies on the relationship between 5 -hydroxytryptamine turnover in brain and tolerance and physical dependence in mice. J. Pharmacol. Exp. Ther. 178, 20-29 (1971) 